\title{
Aspectos clínico-patológicos e epidemiológicos da endocardite bacteriana em cães: 28 casos (2003-2008)
}

\section{The clinicopathological and epidemiological aspects of bacterial endocarditis in dogs: 28 cases (2003-2008)}

\author{
Diogo Kazuya Cavaguchi ${ }^{1}$; Vanessa Andréa Pincelli; \\ Mariana Menezes Bochio ${ }^{3}$; Rita de Cássia Lima Ribeiro ${ }^{4}$; \\ Ana Paula Frederico Rodrigues Loureiro Bracarence ${ }^{5}$; Patrícia Mendes Pereira ${ }^{6 *}$
}

\section{Resumo}

O presente trabalho objetivou revisar os aspectos clínico-patológicos e relatar os dados obtidos sobre a endocardite bacteriana em cães, por meio de estudo retrospectivo realizado nos arquivos do Hospital Veterinário e Laboratório de Patologia Animal da Universidade Estadual de Londrina (UEL), durante o período de janeiro de 2003 a maio de 2008. No transcorrer do período considerado, 28 cães apresentaram a doença, sendo 50\% machos e 50\% fêmeas. Animais de médio a grande porte foram os mais acometidos e os adultos obtiveram maior prevalência. Os principais sinais clínicos apresentados foram apatia, hiporexia, hipertermia, esplenomegalia, dispnéia, desidratação, disúria e sopro cardíaco. À necropsia, observou-se que a válvula mitral foi a estrutura cardíaca mais afetada, sendo o rim o órgão mais frequentemente acometido.

Palavras-chave: Cães, endocardite, epidemiologia, septicemia, bactéria

\begin{abstract}
The aim of this study was to review the clinicopathological aspects and report the data obtained from bacterial endocarditis cases in dogs. A restropective study was carried out based on files of the Veterinary Hospital and the Animal Pathology Laboratory of Universidade Estadual de Londrina (UEL) from January 2003 to May 2008. During this period, 28 dogs presented bacterial endocarditis, 50\% males and $50 \%$ females. Medium to large dogs were the most affected and adult animals were prevalent, with the following clinical signs: apathy, hiporexy, hyperthermia, splenomegaly, dyspnea, dehydration, dysuria and cardiac murmur, Necropsy revealed the mitral valve as the most affected cardiac structure and among the organs, the kidneys were the most affected.
\end{abstract}

Key words: Dogs, endocarditis, epidemiology, septicemia, bacteria

1 Graduação em Medicina Veterinária - Universidade Estadual de Londrina - UEL - Paraná. E-mail: diogokc@hotmail.com

2 Graduação em Medicina Veterinária - Universidade Estadual de Londrina - UEL

3 Graduação em Medicina Veterinária - Universidade Estadual de Londrina - UEL

4 Programa de Residência em Patologia Animal - Departamento de Veterinária Preventiva - Universidade Estadual de Londrina UEL

5 Professor Associado - Laboratório de Patologia Animal - Departamento de Veterinária Preventiva - Universidade Estadual de Londrina - UEL - Paraná

6 Professor Adjunto - Área de Clínica Médica de Animais de Companhia - Departamento de Clínicas Veterinárias - Universidade Estadual de Londrina - UEL - Paraná. E-mail: pmendes@uel.br

* Autor para correspondência 


\section{Introdução}

A endocardite bacteriana é uma infecção do endocárdio valvular e/ou mural de baixa prevalência em cães, porém com alta morbidade e mortalidade (MILLER; FOX; SAUDERS, 2004; WARE, 2006). Os cães machos de médio a grande porte, adultos, são descritos como os mais predispostos (O'GRADY, 2004; SYKES et al., 2006). Um quadro de bacteremia, persistente ou transitório, precisa se estabelecer previamente, para acarretar uma eventual infecção secundária do endocárdio. Assim sendo, processos infecciosos originalmente localizados, como afecções cutâneas, orais, urinárias e prostáticas ou em outros órgãos, podem resultar em bacteremia com a evolução e complicação do quadro clínico. Procedimentos contaminados (odontológicos, endoscopia, cateterização vesical e cirurgia anal), também podem causar bacteremia transitória, e conseqüentemente endocardite (MILLER; FOX; SAUDERS, 2004; SPAGNOL et al., 2006; WARE, 2006).

A válvula mitral e a válvula aórtica são as mais comumente acometidas. A colonização microbiana acarreta em ulceração do endotélio valvular e exposição do colágeno subendotelial, que estimula a agregação plaquetária e a ativação da cascata de coagulação. Seqüencialmente, há a formação de vegetações, as quais causam deformações valvulares, incluindo perfurações ou rompimentos do folheto ou folhetos, resultando em insuficiência cardíaca (MILLER; FOX; SAUDERS, 2004; SPAGNOL et al., 2006).

$\mathrm{Na}$ maioria das vezes, a lesão é decorrente da colonização das válvulas por agentes infecciosos, especialmente bactérias. Contudo, há que se considerar infecções estabelecidas por fungos, riquétsias e clamídias (FIGHERA, SOUZA; IRIGOYEN, 2007). Dentre os microorganismos potencialmente envolvidos, destacam-se Streptococcus spp., Staphylococcus spp., Escherichia coli, Corynebacterium sp., Pasteurella sp., Pseudomonas aeruginosa, Erysipelothrix rhusiopathiae, Bartonella vinsonii subsp. Berkoffii, Bartonella henselae, Bartonella clarridgeiae, Proteus spp. (BROWN, 2004; MILLER; FOX; SAUDERS, 2004; O'GRADY, 2004; PESAVENTO et al., 2005).

As conseqüências e a severidade da endocardite dependem de diversos fatores, tais como virulência do agente infeccioso, órgão de choque, duração da infecção, grau de destruição valvular, influência da vegetação na estrutura e função valvular e formação de complexos imuno-mediados (MILLER; FOX; SAUDERS, 2004; O'GRADY, 2004).

As manifestações clínicas são variadas e inespecíficas, o que compromete o estabelecimento de diagnóstico nosológico conclusivo. O diagnóstico definitivo normalmente é feito no exame postmortem. Contudo, os sinais clínicos freqüentemente relatados são anorexia, sopro cardíaco, arritmias, letargia, perda de peso, inapetência, distúrbios gastrointestinais, claudicação, taquipnéia, pulso femoral hipercinético, dispnéia, dentre outros. Dependendo dos órgãos acometidos por complexos imuno-mediados ou por êmbolos sépticos, extremidades frias, cianose, necrose dérmica e distúrbios neurológicos podem contribuir para o clínico suspeitar da doença (MILLER; FOX; SAUDERS, 2004; O'GRADY, 2004; SPAGNOL et al., 2006; WARE, 2006; FIGHERA; SOUZA; IRIGOYEN, 2007).

As arritmias desenvolvem-se em conseqüência da invasão bacteriana do miocárdio, acometendo 40 a $70 \%$ dos animais. $\mathrm{O}$ embolismo, propiciado pelas formações vegetativas em porções coronarianas, resulta em vasculite imuno-mediada e hipóxia. Arritmias graves tais como taquicardia ventricular, fibrilação atrial e completo bloqueio cardíaco, podem ser também observadas (MALIK; ZUNINO; HUNT, 2003; MILLER; FOX; SAUDERS, 2004; MACDONALD, 2009).

Baseado nos achados clínicos e laboratoriais, hemoculturas, eletrocardiograma e ecocardiografia, um diagnóstico presuntivo 
poderá ser estabelecido (SPAGNOL et al., 2006; WARE, 2006). A sensibilidade da hemocultura é de aproximadamente $80 \%$. Os resultados negativos, entretanto, podem ser consequência de administração recente de antibióticos, endocardite crônica e bacteremia intermitente (MILLER; FOX; SAUDERS, 2004).

A ecocardiografia tem facilitado, sobremaneira, o diagnóstico e a monitoração dos pacientes, revelando-se ferramenta valiosa na mensuração de alterações secundárias na silhueta cardíaca e ana valiação funcional e estrutural das válvulas, assim como a vibração ocasionada pela regurgitação aórtica. Algumas conseqüências das vegetações valvulares podem ser observadas, como avulsão da válvula mitral, dilatação de câmaras cardíacas, insuficiência do miocárdio e formação de abscessos. Vegetações pequenas podem ser difíceis de visualizar, principalmente em animais pequenos, obesos ou com dispnéia. No início da doença, as lesões caracterizam-se por um discreto espessamento valvular e /ou aumento da ecogenicidade (O'GRADY, 2004; WARE, 2006; QUINTAVALLA; MAVROPOULOU, 2007).

$\mathrm{Na}$ avaliação do eletrocardiograma, os resultados podem ser normais ou ter alterações como batimentos prematuros, taquicardias, distúrbios de condução, evidência de isquemia miocárdica e bloqueio átrio ventricular de primeiro, segundo ou terceiro graus (WARE, 2006).

Os achados laboratoriais mais usuais são relativos a processos inflamatórios, apresentando neutrofilia com desvio à esquerda em casos agudos e neutrofilia com monocitose em doenças crônicas. Anemia não regenerativa, azotemia, fosfatase alcalina (FA) elevada, hipoalbuminemia, hipoglicemia, hiperglobulinemia, hematúria, piúria e proteinúria podem ser verificadas. No exame radiográfico pode ser encontrado aumento da silhueta cardíaca e edema pulmonar em casos mais avançados (MILLER; FOX; SAUDERS, 2004; SYKES et al., 2006; WARE, 2006). Em um estudo realizado em
71 cães com endocardite, 61 animais passaram por avaliação laboratorial e as alterações mais freqüentes foram: leucocitose $(89 \%)$, trombocitopenia $(50 \%)$, anemia não regenerativa (41\%), hipoalbuminemia (95\%), alanina aminotransferase (ALT), FA ou gama glutamil transferase elevadas (GGT) (70\%); azotemia (42\%), creatinina elevada (28\%), proteinúria $(62 \%)$, hematúria $(62 \%)$ e piúria $(60 \%)$. No mesmo estudo, alterações cardiopulmonares foram observadas ao exame radiográfico em $67,8 \%$ dos animais. Cardiomegalia generalizada (40\%), infiltrado pulmonar intersticial focal ou difuso, ou infiltrado broncointersticial (37,8\%), átrio esquerdo aumentado $(31,1 \%)$ e infiltrado alveolar $(22,2 \%)$ foram as alterações mais freqüentes (SYKES et al., 2006).

O objetivo da terapia é eliminar os focos de infecção e realizar o tratamento de todas as complicações secundárias. Preconizase antibioticoterapia agressiva e imediata, preferencialmente, de acordo com os resultados de cultura e antibiograma. Porém, enquanto se espera os resultados destes exames, recomenda-se antibióticos como cefalosporina, penicilina, aminoglicosídeos ou fluoroquinolonas, via intravenosa ou intramuscular na primeira semana e posteriormente por via oral durante quatro a seis semanas, no mínimo. A função renal deve ser monitorada quando os aminoglicosídeos são utilizados em decorrência de sua nefrotoxicidade. O tratamento de suporte deve ser iniciado quando estiverem presentes arritmias e insuficiência cardíaca congestiva (ICC), distúrbios eletrolíticos e problemas nutricionais (MILLER; FOX; SAUDERS, 2004; O'GRADY, 2004; WARE, 2006).

O prognóstico de endocardite bacteriana varia entre reservado e ruim. A longo prazo, muitos cães vêm a óbito ou os proprietários optam pela eutanásia. O prognóstico torna-se reservado em casos de envolvimento exclusivo da válvula mitral, nas infecções por Gram-positivos e nos casos em que a origem da infecção é a pele, seja por abscessos, celulites ou ferida infectadas. O prognóstico ruim 
estabelece-se em situações que tanto o diagnóstico clínico definitivo, quanto o início da terapia corretiva são realizados tardiamente, bem como nos casos de vegetações em diversas válvulas, arritmias severas e insuficiência cardíaca não responsiva, além de lesões em outros sistemas (O'GRADY,2004; FREEMAN; RUSH; FARABAUGH, 2005; WARE, 2006).

Este estudo tem como objetivo revisar os aspectos clínicos e a incidência da endocardite bacteriana por meio de avaliação retrospectiva realizada no Hospital Veterinário da Universidade Estadual de Londrina, no período de 2003 a 2008, assim como comparar as freqüências dos dados obtidos com as de literatura.

\section{Material e métodos}

Foi realizado um estudo retrospectivo nos arquivos do Hospital Veterinário e Laboratório de Patologia Animal da Universidade Estadual de Londrina, durante o período de janeiro de 2003 a maio de 2008. As informações foram obtidas a partir dos relatórios de necrópsia e fichas clínicas dos pacientes que continham informações de peso, idade, raça, sexo, sinais clínicos, resultados de exames laboratoriais e achados de necropsia.

O diagnóstico definitivo de endocardite bacteriana foi obtido por meio da visualização das afecções como inflamação das válvulas cardíacas, tromboembolismo arterial e infartos em órgãos e tecidos. A ocorrência de sinais clínicos como ICC, edema e congestão pulmonar, fígado com congestão passiva crônica e efusões, também foram avaliados. A determinação da porta de entrada das bactérias e o sítio de infecção primária tiveram como base o histórico e os achados clínicos do paciente. Para comparar as freqüências encontradas com as de literatura utilizou-se o Teste G, sendo adotado o nível de significância de 5\%.

\section{Resultados}

Foram revisados 733 laudos anatomopatológicos de cães, do período de janeiro de 2003 a maio de 2008. Destes, 28 foram diagnosticados com endocardite bacteriana, correspondendo a 3,81\% do total das necropsias realizadas durante o período considerado. Dentre os pacientes, aponta-se 14(50\%) machos e 14 (50\%) fêmeas. A raças observadas foram Rottweiler (4/28), Cocker Spaniel Inglês (3/28), Fila Brasileiro (2/28), Collie (2/28), Poodle (2/28), Basset Hound (2/28]), Pastor Belga (1/28), Pitt Bull (1/28), São Bernardo (1/28), Teckel (1/28) e sem raça definida (SRD) (9/28). Dentre os animais de raça, 11 (57,9\%) foram representados por cães de grande porte ou gigante. A idade dos animais variou de cinco meses a 16 anos. Os adultos tiveram maior prevalência, sendo que $78,6 \%$ (22/28) dos animais afetados apresentavam idade acima de quatro anos.

Os animais avaliados apresentaram uma grande variação nos sinais clínicos, os principais sinais estão representados na Tabela 1.

À necropsia, as válvulas acometidas foram mitral, tricúspide, mitral e tricúspide, tricúspide e aórtica. Lesões murais também foram observadas tanto isoladamente, quanto associadas às válvulas mitral, pulmonar e mitral e tricúspide (Tabela 2). Os principais achados histológicos foram infiltrado neutrofílico e linfo-plasmocitário no endocárdio e miocárdio, com presença de colônias bacterianas e necrose focal ou multifocal do miocárdio. 
Tabela 1. Distribuição dos sinais clínicos apresentados pelos 28 casos de endocardite bacteriana. Londrina, 2008.

\begin{tabular}{ccc}
\hline Sinais Clínicos & $\mathbf{N}^{\mathbf{0}}$ de Animais & \% \\
\hline Apatia & 21 & 75 \\
Hiporexia & 15 & 53,6 \\
Hipertermia & 10 & 35,7 \\
Esplenomegalia & 9 & 32,1 \\
Dispnéia & 8 & 28,6 \\
Desidratação & 7 & 25 \\
Disúria & 7 & 25 \\
Sopro Cardíaco & 7 & 25 \\
Vômito & 6 & 21,4 \\
Claudicação & 5 & 17,8 \\
Dor abdominal & 5 & 17,8 \\
Secreção ocular & 5 & 17,8 \\
Ataxia & 4 & 14,3 \\
Icterícia & 4 & 14,3 \\
Lesões de pele & 4 & 14,3 \\
Palidez de mucosas & 4 & 14,3 \\
Secreção vaginal purulenta & 4 & 14,3 \\
Atralgia & 3 & 10,7 \\
Convulsão & 3 & 10,7 \\
Diarréia & 3 & 10,7 \\
Epistaxe & 3 & 10,7 \\
Paresia de membros & 3 & 10,7 \\
\hline & &
\end{tabular}

Tabela 2. Distribuição das lesões valvulares e murais observadas no exame anatomopatológico dos 28 casos de endocardite bacteriana em cães. Londrina, 2008.

\begin{tabular}{ccc}
\hline Estrutura acometida & $\mathbf{N}^{\mathbf{0}}$ de animais & $\mathbf{\%}$ \\
\hline Mitral & 11 & 39,3 \\
Tricúspide & 4 & 14,3 \\
Mitral e tricúspide & 4 & 14,3 \\
Mural & 4 & 14,3 \\
Mural e mitral & 2 & 7,1 \\
Mural, mitral e tricúspide & 1 & 3,6 \\
Mural e pulmonar & 1 & 3,6 \\
Tricúspide e aórtica & 1 & 3,6 \\
\hline Total & 28 & $100 \%$ \\
\hline
\end{tabular}


Os órgãos envolvidos, com sinais de necrose isquêmica e/ou hemorragia, foram rins (19/28 [67,8\%]), coração (miocárdio) (9/28 [32,1\%]), cérebro (7/28 [25\%]), fígado (7/28 [25\%]), pulmão $(6 / 28[21,4 \%])$, baço $(4 / 28[14,3 \%])$, pâncreas $(3 / 28$ $[10,7 \%])$, intestino $(3 / 28[10,7 \%])$, estômago $(1 / 28$ [3,6\%]) e língua $(1 / 28[3,6 \%])$

Achados de necropsia sugestivos de ICC foram observados em 23 (82,1\%) cães. Destes, 17 (73,9\%) apresentavam edema/congestão pulmonar e seis $(26,1 \%)$ apresentavam fígado em noz moscada ou congestão do órgão.

Como possíveis determinantes das portas de entrada dos agentes elencam-se as lesões cutâneas (8/28 [28,6\%]), endometrite (5/28 [17,8\%]), gastroenterite hemorrágica $(4 / 28$ [14,3\%]), nódulos mamários ulcerados $(3 / 28[10,7 \%])$, cisto prostático $(3 / 28[10,7 \%])$ e otite crônica $(2 / 28[7,1 \%])$.

As alterações laboratoriais encontradas nesses cães foram: anemia (11/28 [39,3\%]), leucocitose $(10 / 28[35,7 \%])$, fosfatase alcalina aumentada (9/28 [32,1\%]), pancitopenia $(5 / 28[17,8 \%])$, creatinina elevada $(5 / 28[17,8 \%])$ e trombocitopenia (4/28 [14,3\%]). Em apenas dois animais a hemocultura foi realizada, sendo isolados os seguintes agentes: as bactérias Acinetobacter spp. e Hafnia spp.

O tratamento realizado nos pacientes foi preconizado de acordo com a doença primária utilizando os fármacos em ajuste com os principais sinais clínicos. A cimetidina, ranitidina e metoclopramida, foram prescritos para os animais com distúrbios gastrointestinais; diazepam e fenobarbital, para aqueles com distúrbios neurológicos; a morfina, tramadol e dipirona, para o controle da dor; e enalapril, digoxina e furosemida, nos cães que já apresentavam sinais de descompensação cardíaca. A prednisona e o cetoprofeno como antiinflamatórios. A terapia antimicrobiana preconizada, também teve como base a doença primária. Os fármacos foram utilizados de forma isolada ou associados na seguinte proporção: enrofloxacina (8/28 [28,6\%]), doxiciclina $(6 / 28 \quad[21,4 \%])$, metronidazol $(5 / 28$
$[17,8 \%])$, cefalexicina $(5 / 28 \quad[17,8 \%])$, imizol $(4 / 28[14,3 \%])$, sulfa-trimetropim $(3 / 28[10,7 \%])$, gentamicina $(2 / 28[7,1 \%])$, cefalotina $(1 / 28[3,6 \%])$ e rifampicina $(1 / 28[3,6 \%])$.

A sobrevida dos pacientes variou de um dia a 20 dias, com média de quatro dias e meio.

\section{Discussão}

A prevalência da doença neste estudo $(3,81 \%)$ encontra-se de acordo com a literatura americana, que varia de $0,04 \%$ a 6,6\% (BROWN, 2004; MILLER; FOX; SAUDERS, 2004; PEDDLE; SLEEPER, 2007).

Em relação ao sexo, o número de machos afetados foi equivalente ao de fêmeas, diferindo dos resultados de Fighera, Souza e Irigoyen(2007), Sykes et al. (2006) e Spagnol et al. (2006), que obtiveram frequência de machos acometidos superior a de fêmeas, com incidências de 69,4\%,66,2\% e 59,2\%, respectivamente. Não houve diferença significativa $(p>0,05)$ entre a freqüência obtida e a encontrada na literatura.

A idade mais frequente dos animais acometidos foi a adulta, estando de acordo com dois autores, que relatam que grande parte dos animais afetados apresentavam mais de quatro ou cinco anos de idade (WOODFIELD; SISSON, 1992; SYKES et al., 2006).

Em um estudo realizado com 72 casos de endocardite bacteriana em cães, 45,8\% não tinham raça definida e 54,2\% eram de raça; destes, 92,3\% eramde raças de grande porte ou gigantes(FIGHERA, SOUZA; IRIGOYEN, 2007). Em outro trabalho que descreve 54 casos, os cães de raça $(68,5 \%)$ também prevaleceram sobre os SRD (31,5\%). Além disso, dentre os animais de raça, os cães de grande porte ou gigantes $(86,5 \%)$ também foram predominantes sobre os demais (SPAGNOL et al., 2006). Neste estudo, os cães de raça $(67,9 \%)$ também foram mais freqüentes que os $\operatorname{SRD}(32,1 \%)$. E dentre os animais de raça, 11 (57,9\%) eram de grande porte ou gigante. Houve diferença significativa entre as porcentagens de animais de raça e SRD quando 
comparadas a Fighera, Souza e Irigoyen (2007), porém não houve quando comparadas a Spagnol et al. (2006). A porcentagem de raças de grande porte/ gigante observadas neste estudo difere $(\mathrm{p}<0,05)$ das relatadas na literatura.

Fighera, Souza e Irigoyen (2007), Spagnol et al. (2006) e Sykes et al. (2006) classificaram também as válvulas mais afetadas nos animais com endocardite bacteriana. A válvula mitral isoladamente foi a mais acometida(66,7\%, 85,2\% e 39,4\%, respectivamente) em todos os estudos, achado semelhante ao obtido no presente levantamento (39,3\%). A freqüência de acometimento da válvula mitral não difere de forma significativa apenas quando comparada a Sykes et al. (2006).

A maior incidência na válvula mitral pode estar relacionada com o fato das válvulas do lado esquerdo do coração serem submetidas a maior pressão biomecânica, causando uma maior predisposição a microtraumatismos, favorecendo a colonização da superfície endocárdica por bactérias (JONES; HUNT; KING, 2000; MILLER; FOX; SAUDERS, 2004).

A válvula tricúspide foi a segunda válvula mais acometida isoladamente (14,3\%). Segundo a literatura, a incidência foi de $4,2 \%, 1,8 \%$ e $2,8 \%$ respectivamente (FIGHERA; SOUZA; IRIGOYEN, 2007, SPAGNOL et al., 2006; SYKES et al., 2006). Não houve significância com relação a Fighera, Souza e Irigoyen (2007).

Associações entre as válvulas mitral e tricúspide também foram descritas tanto no presente estudo $(14,3 \%)$, quanto em outros estudos $(6,9 \%, 3,7 \%$ e $2,8 \%$ respectivamente) (FIGHERA; SOUZA; IRIGOYEN, 2007, SPAGNOL et al., 2006; SYKES et al., 2006). Houve diferença significativa apenas com Sykes et al. (2006).

Lesões murais isoladas foram encontradas em 14,3\% dos cães, não havendo significância com as freqüências de Spagnol et al. (2006) e Sykes et al. (2006), com 5,6\% e 8\%, respectivamente.

A estenose subaórtica é relatada como fator predisponente por alguns autores (MILLER;
FOX; SAUDERS, 2004; SELVARAJ et al., 2006; FIGHERA; SOUZA; IRIGOYEN, 2007; PEDDLE; SLEEPER, 2007). No entanto, dos animais com diagnóstico de endocardite bacteriana avaliados, nenhum deles apresentava estenose subaórtica.

A principal complicação associada à endocardite bacteriana em animais domésticos é o infarto secundário ao tromboembolismo (SYKES et al., 2006). O órgão mais envolvido foi o rim (19/28), concordando com o descrito na literatura (SPAGNOL et al., 2006; SYKES et al., 2006; FIGHERA; SOUZA; IRIGOYEN, 2007). A freqüência encontrada difere apenas de Sykes et al. (2006), sem apresentar diferença significativa com os demais.

Também segundo a literatura, o segundo órgão mais acometido é o baço, com incidência de 44,4\%, $14,1 \%$ e $31,9 \%$ respectivamente (SPAGNOL et al., 2006; SYKES et al., 2006; FIGHERA; SOUZA; IRIGOYEN, 2007). Porém, no presente estudo o baço foi o sexto órgão mais acometido, apesar de ter uma porcentagem aproximada $(14,3 \%)$ à obtida por Sykes et al. (2006).

De acordo com Spagnol et al. (2006) e Fighera, Souza e Irigoyen (2007), foram observados achados indicativos de ICC em 53,7\% e 18\% dos cães com endocardite bacteriana, respectivamente. Neste estudo, as alterações na necropsia sugestivas de ICC foram encontrados em $23(82,1 \%)$ cães, havendo diferença significativa com os demais autores.

Em relação aos sinais clínicos apresentados, apatia, hiporexia e febre tiveram maior incidência tanto neste estudo quanto na literatura consultada (BROWN, 2004; SYKES et al., 2006; FIGHERA; SOUZA; IRIGOYEN, 2007). Porém, a porcentagem de animais que apresentaram sopro cardíaco $(25 \%)$ foi menor que a porcentagem relatada por Sykes et al., (2006) e Fighera, Souza e Irigoyen (2007), sendo de $59,2 \%$ e $37,5 \%$ respectivamente. Esta diferença pode ser decorrente de falhas na auscultação cardíaca ou pelas características e localização das lesões valvulares. 
As mais relevantes portas de entrada dos agentes infecciosos encontradas neste estudo foram lesões cutâneas $(28,6 \%)$ e distúrbios ginecológicos/ andrológicos (28,6\%), achados semelhantes à literatura. No estudo elaborado por Fighera, Souza e Irigoyen (2007), do total de cães em que uma aparente causa de endocardite pôde ser estabelecida, 37,2\% apresentavam lesões cutâneas não exsudativas e $32,6 \%$ apresentavam distúbios ginecológicos/andrológicos.

\section{Conclusão}

Este trabalho traz informações sobre dados de incidência, patofisiológicos, sinais clínicos e diagnósticos importantes sobre casos de endocardite bacteriana em cães. Embora muitas freqüências estejam próximas das de outros estudo, há uma grande variação dos dados encontrados em relação à literatura, assim como entre os diferentes autores citados. O conhecimento destes dados é uma importante ferramenta para o clínico na orientação da abordagem diagnóstica, visto que quanto mais rápida a abordagem e o início do tratamento, maiores serão as chances de sobrevida do paciente.

\section{Referências}

BROWN, V. A. Aortic vavular endocarditis in a dog. The Canadian Veterinary Journal, Ottawa, v. 45, n. 8, p. 682684, 2004.

FIGHERA, R. A.; SOUZA, T. M.; IRIGOYEN, L. F. Aspectos epidemiológicos e clínicopatológicos de 72 casos de endocardite valvar em cães. Clinica Veterinária, São Paulo, v. 67, n. 12, p. 60-67, 2007.

FREEMAN, L. M.; RUSH, J. E.; FARABAUGH, A. E. Development and evaluation of a questionnaire for assessing helth-related quality of life in dog with cardiac disease. Journal of American Veterinary Medical Association, Schaumburg, v. 226, n. 11, p. 1864-1868, 2005.

JONES, T. C.; HUNT, R. D.; KING, N. W. Sistema cardiovascular. In: . Patologia Veterinária. 6. ed. São Paulo: Manole, 2000. p. 991-1025.

MACDONALD, K. A. Infective endocarditis. In: BONAGURA, J. D.; TWEDT, D. C. Current Veterinary
Therapy. 14. ed. St. Louis: Saunders Elsevier, 2009. p. 786-791.

MALIK, R.; ZUNINO, P.; HUNT, G. B. Complete heart block associated with lupus in a dog. Australian Veterinary Journal, Sydney, v. 81, n. 7, p. 398-401, 2003.

MILLER, M. W.; FOX, P. R.; SAUDERS, A. B. Pathologic and clinical features of infectious endocarditis. Journal of Veterinary Cardiology, Amsterdam, v. 6, n. 2, p. 3545, 2004.

O'GRADY, M. R. Cardiopatia valvular adquirida. In: ETTINGER S, J.; FELDMAN, E. Tratado de medicina interna veterinária. 5. ed. Rio de Janeiro: Guanabara Koogan, 2004. v. 1, p. 842-845.

PEDDLE, G.; SLEEPER, M. M. Canine bacterial endocarditis: a review. Journal of the American Animal Hospital Association, Lakewood, v. 43, n. 5, p. 258-263, 2007.

PESAVENTO, P. A.; CHOMEL, B. B.; KASTEN, R. W.; MCDONALD, K. A.; MOHR, F. C. Pathology of bartonella endocarditis in six dogs. Veterinary Pathology, Middleton, v. 42, n.3, p. 370-373, 2005.

QUINTAVALLA, C.; MAVROPOULOU, A.; BURATTI, E. Aortic endocarditis associated with a perforated septal membranous aneurysm in a boxer dog. Journal of Small Animal Practice, Oxford, v. 48, n. 6, p. 330-334, 2007.

SELVARAJ, J.; MANOHAR, B. M.; PRABAKAR, T. G.; BALACHANDRAN, C.; MAHESH, M. Bilateral atrioventricular vegetative endocarditis in a dog. Indian Veterinary Journal, Madras, v. 83, n. 6, p. 686-687, 2006.

SPAGNOL, C.; LORETTI, A. P.; OLIVEIRA, E. C.; OlIVEIRA, R. T.; DRIEMEIER, D. Aspectos epidemiologicos da endocardite bacteriana em cães: 54 casos (2000-2005). Acta Scientiae Veterinariae, Porto Alegre, v. 34, n. 3, p. 255-260, 2006.

SYKES, J. E.; KITTLESON, M. D.; CHOMEL, B. B.; MACDONALD, K. A.; PESAVENTO, P. A. Clinicopathologic findings and outcome in dogs with infective indocarditis: 71 cases (1992-2005). Journal of American Veterinary Medical Association, Schaumburg, v. 228, n. 11, p. 1735-1746, 2006.

WARE, W. A. Disturbios do sistema cardiovascular. In: NELSON, R. W.; COUTO, C. G. Medicina interna de pequenos animais. 3. ed. Rio de Janeiro: Elsevier, 2006. p. 142-146.

WOODFIELD, J. A.; SISSON, J. Endocardite infecciosa. In: ETTINGER, S. J. Tratado de medicina interna veterinária: moléstias do cão e do gato. 3. ed. São Paulo: Manole, 1992. p. 104-112. 